\title{
Analysing the Effectiveness of Sector Support: Primary Education in Uganda and Zambia
}

\author{
Antonie de Kemp
}

\begin{abstract}
1 Introduction
Since the mid-1990s, development agencies, including the Netherlands, started to move from project aid towards sector and general budget support. These new aid modalities emerged because of a perceived lack of efficiency and effectiveness of the project approach, due to fragmentation and a lack of coordination, ownership and sustainability. The new aid policy has important implications for the evaluation of the effectiveness of bilateral support. Instead of focusing on the contribution of a specific development agency, an evaluation should focus on the sector as a whole. This article summarises two evaluations of the impact of interventions in primary education in Uganda and in Zambia (IOB/MoES 2008; IOB/AIID 2007). The objectives of the article are to show how the impact of developments in the sector can be analysed with the use of secondary data and to sketch the results in the education sector in these two countries.
\end{abstract}

\section{The evaluation problem}

In general, it is difficult to give a statistically unbiased assessment of the effectiveness of development programmes. They may seem to be effective or not, but many factors besides the direct interventions may have influenced the results. Outcomes may be affected by many other variables than (government) interventions. In education, the social background of pupils, economic developments, conflict situations, etc. may have an impact as well. Here one touches upon the problem of the counterfactual: what would have been the outcome in the absence of the intervention? Three related problems are at stake. First, there is the attribution problem. An unbiased assessment of the effect of educational interventions on, for instance, enrolment has to take into account the effects of differences in size, remoteness, or poverty status of the households, as these factors may also influence enrolment. Enrolment rates may increase because of higher incomes, the lowering or abolition of school and exam fees, a greater parental awareness of the importance of education, etc. Poor education outcomes may be due either to low quality of the schooling system (teachers, teaching methods, materials), to underfunding or to factors that are beyond the education policy itself. The attribution problem is related to selection effects. They may occur when the intervention group(s) and control group(s) have different characteristics. The neglect of these effects may lead to biased estimates (White, Sinha and Flannagan 2006: 3-4). For instance, many studies find that repeaters have lower test and examination results than pupils who did not repeat. Several authors conclude from this that repetition does not help and that it is just a waste of resources. However, such a conclusion seems to neglect selection effects: intelligent children with well-educated parents will have good results and therefore will not repeat. In addition, poor and/or less intelligent children will not have good results and therefore they will have a higher chance to repeat. Both groups of pupils are not the same and this makes it impossible to draw conclusions based on a comparison between the two. As long as selection is based on observable (measurable) characteristics, those characteristics may be included in the analysis. However, they are not always observed. This is the third problem, the selection on unobservables. Class size may be endogenous and may be correlated with the socioeconomic background of parents (see for instance Glewwe and Kremer 2005). The choice of motivated (and probably welleducated) parents is correlated with (for instance) 
class size, as these parents tend to send their children to schools with low pupil-teacher ratios.

The shift towards new aid modalities raises new questions. Rigorous methods for evaluating impact are designed for projects rather than sector aid or general budget support. Moreover, at the higher level of aggregation, the interventions to be evaluated are heterogeneous (Elbers and Gunning 2006). A project or programme has a clear-cut start, but this is not necessarily so at the sectoral level. This makes it more difficult to measure the before and after situation. In many cases, the intervention is not discrete and not necessarily targeted at a specific group. Therefore, it will be difficult to establish the counterfactual. Moreover, the heterogeneity of influences makes it more difficult to isolate specific interventions from the rest. Problems of contagion will be all-pervasive.

\section{Methodology}

The two studies described here tried to solve the methodological problems in the following ways:

- a description of the factual

- elaboration of the intervention theory;

- a statistical, regression-based, analysis;

- triangulation;

- the exploitation of natural restrictions.

Both studies started with an analysis of developments in the sector based on the literature, documents of the ministries involved and the inclusion of local consultants and experts from the Ministry and related agencies in the research team. Next came the development of the intervention theory on the basis of the literature (see especially White 2004; Kingdon 2005; Verspoor 2006). The intervention model relates investments in school management, teachers, classrooms, books, and other facilities to specific outcomes such as access and learning achievements. ${ }^{1}$ Moreover, it includes specific school characteristics as well as pupil, parent, and regional characteristics in order to deal with selection effects. The model contributes to focused theory-based data-gathering and assures that the statistical analysis is based on the testing of hypotheses rather than on data mining, which would lead to (statistically) biased results. The studies use a regression-based approach in which the interventions or outputs at the school and other school characteristics as well as pupil, household, and regional characteristics are regressors and access and learning achievement are the dependent variables. The main unit of analysis is the school.

The studies are mainly based on the analysis of secondary data. The use of secondary data creates many challenges as well as several new opportunities. The most important sources of information used are:

- annual school census data (for the years 2000-2005);

- national assessment tests

- examination data (at grade 7)

- Demographic and Health Surveys (DHS), especially the EdData Surveys;

- the Population and Housing Census;

- SACMEQ || data; ${ }^{2}$

- specific surveys for these studies (including a survey on teacher absenteeism).

The heart of the analysis consists of linking EMIS data (school census data in the Education Management Information System) to test and examination results at the school level. The evaluations use DHS surveys and Population Census data for household and regional differences. With school management data for two districts it was possible to analyse the effects of effective management (in Uganda). Linking data made testing the reliability of the data possible. For instance the plausibility of enrolment figures (at the school level) was tested by comparing these figures over time, as well as comparing the enrolment figures at grade 7 with the examination data at grade 7 . Other tests checked the consistency of data (by comparing the variables with each other; for instance, pupil-teacher ratios, the number of repeaters in comparison with the total number of pupils, etc.).

The use of secondary data has some disadvantages as well. Not all school data appear to be reliable and this may contribute to a large measurement error. This reduced the possibility of using instrumental variables or 'double difference' to get rid of unobserved selection effects. Nevertheless, the robustness of results has been checked through triangulation and the exploitation of natural restrictions. The preceding paragraph mentioned the example of a correlation between class size and the choice of parents. When this correlation exists, a solution is the estimation of effects in situations 
where parents do not have a choice (that is in remote rural areas). ${ }^{3}$ Finally, both studies have been using the technique of propensity score matching to analyse the effect of specific programmes.

\section{Education policy}

Of the two countries, Uganda was the first to launch an ambitious investment plan that aimed at realising the Millennium Development Goals for education. Prior to the introduction of Universal Primary Education (UPE) in 1997, the status of the primary education sub-sector in Uganda was dismally poor. Budgetary allocations to the education sector declined from 3.4 per cent to 1.4 per cent between 1971 and 1985. The physical infrastructure had deteriorated or was completely destroyed and the teachers' take-home pay had fallen far below acceptable levels. In 1986, the Government of Uganda (GoU) initiated a process of reforming and reconstructing the education system. This process resulted in the Government White Paper on Education of 1992. In 1996, president Museveni announced, upon his election to presidency, free primary education for the first four children per family. Difficulties in establishing the eligibility criteria forced the government to abandon the 'four children ceiling' and to extend free education to all schoolage children. These measures resulted in an explosion of enrolment. Between 1995 and 1997, the number of children enrolled in primary education doubled (see next paragraph). At first, this had a negative effect on the quality of education: pupil-teacher ratios and pupil-classroom ratios skyrocketed. Children went to school, but they had to sit on the floor in overcrowded classrooms and lacked learning materials. Large investments were necessary to cope with the shortages of schools, classrooms, teachers, books, and other school facilities.

The increased attention of the GoU to the education sector coincided with donor motivation to shift from projects to sector and budget support (for an overview see Eilor 2004). The idea for the Sector Wide Approach on education in Uganda emerged in 1996 and was realised with the Education Sector Investment Plan (ESIP) for the period 1997-2003. This plan focused on primary education and the move to secondary education. The plan anticipated a total investment of US\$710 million. About 65 per cent was reserved for the basic education sector. In 2005, the MoES adopted the Education Sector Strategic Plan 2004-2015 (ESSP) as a follow-up of the Education
Strategic Investment Plan. While the main objective of the first plan was to get all children into primary school, the second plan recognised that children were not learning basic skills and that it was necessary to invest in the quality of education. The total costs of the new plan were estimated at US\$8 billion, of which US\$5 billion had to be paid by the government and US\$3 billion by the private sector. A Memorandum of Understanding, drafted in 2002, established the specific principles and modalities of the relations between GoU and development agencies. This MoU was never signed, however. Shortly after the introduction of the Sector Wide Approach, the GoU expressed its preference for General Budget Support (GBS) over sector support. From 2000 onwards, the $\mathrm{GoU}$ and development agencies started to develop plans for the transition from sector to budget support and GBS was introduced in 2003/2004. Several donors and development agencies, including the Netherlands, linked their support to the realisation of results in the education sector.

Zambia was a relatively rich country at independence in 1964, but due to erroneous policies and the world economic crisis, the economy collapsed between 1975 and 1990 (see White and Edstrand 1998). As a result, Zambia had to cut the budgets for education and the sector got severely under-funded. At the beginning of the 1990s, the education sector was in a deep crisis as a result of underinvestment for many years. Enrolment rates and literacy rates were falling and the lack of education of the population posed a real hindrance to the social and economic development of the country. The international World Conference on Education for All in 1990 in Jomtien gave an impetus to the education sector, although it took almost ten years before plans developed into concrete action. The MoE policy document Focus on Learning (1992) stressed the mobilisation of resources for the development of formal education in schools. A new boost to education came with Educating Our Future (1996), which addressed the entire formal education system. The next year, in 1997, the GRZ adopted the Education Sector Investment Plan (ESIP). ESIP aimed at improving the coordination of policies and programmes in the education sector as well as the pooling of funding. Several donors and development agencies, including the Netherlands, Ireland Aid, DfID and Norway supported the initiative. The World Bank supported the idea of pooling funds, but thought that ESIP was too ambitious. The World Bank therefore suggested starting with the basic education sector. 
Table 1 Development of enrolment in primary education 1995-2005 (million pupils)

\begin{tabular}{lcccccc}
\hline & $\mathbf{1 9 9 5}$ & $\mathbf{1 9 9 7}$ & $\mathbf{1 9 9 9}$ & $\mathbf{2 0 0 1}$ & $\mathbf{2 0 0 3}$ & $\mathbf{2 0 0 5}$ \\
\hline Uganda & 2.6 & 5.3 & 6.3 & 6.9 & 7.6 & 7.2 \\
Zambia & 1.5 & 1.6 & 1.6 & 1.8 & 2.1 & 2.6 \\
Source EMIS, MoES (Uganda); MoE (Zambia). & & & & \\
\hline
\end{tabular}

This proposal marked the beginning of the Basic Education Sub-Sector Investment Plan (BESSIP). BESSIP addressed issues of access and quality improvement through provision of teaching and learning materials, curricular reform, training of teachers and mainstreaming gender, and decentralisation of education management and administration. BESSIP was planned for the period 1999-2003. Through the implementation of the plan, the MoE sought to realise a 100 per cent enrolment by 2005 with the elimination of repetition and dropout at the same time. As a follow up to BESSIP, the MoE launched in February 2003 a five-year Ministry of Education Strategic Plan (MoESP 2003-2007). This plan created a new stage in the sector cooperation. Until 2003, sector support was mainly restricted to the funding of BESSIP, while the MoESP paved the way for sector support. On the basis of the MoESP, the Ministry of Education and ten development agencies signed in February 2003 a Memorandum of Understanding ( $\mathrm{MoU}$ ) that formed the basis for the sector support. The sector pool became the most important funding modality. In 2003, the GRZ (Government of the Republic of Zambia) funded 75 per cent of the sector budget, while the sector pool contributed 7 per cent. In 2005, the importance of the sector pool had grown to 26 per cent, and the GRZ financed 62 per cent. The rest was financed by other donors.

\section{Results}

In both countries the introduction of free primary education and the abolition of school fees contributed to an expansion of enrolments in primary education. In Uganda, 2.6 million children were enrolled in primary education in 1995. Ten years later, this figure had increased to 7.2 million. Zambia had a later start. There, enrolments were stable until 2000, but then they increased by more than 60 per cent in five years. ${ }^{4}$

With the Education Strategic Investment Plan of 1997-2003 and the later the Education Sector Strategic Plan 2004-2015, the Ministry of Education and Sports (MoES) in Uganda sought to redress the negative effects of this sharp increase. Many new teachers were recruited and trained. The number of teachers almost doubled from 74,000 in 1995 to 145,000 in 2005 (including private schools and community schools). Notwithstanding this growth, the percentage of untrained teachers decreased from 28 per cent to 12 per cent. The number of schools increased from 12,500 in 2000 to 15,000 in 2005. The number of classrooms showed a growth from 68,000 in 2000 to almost 100,000 in 2005. In this period, the number of books for the four main subjects increased from 6.6. million to 10.6 million. As a result of the investments, the pupil-teacher ratio could decrease from 59:1 in 2000 to 50:1 in

Table 2 Development of pupil-teacher ratios and pupil-classroom ratios

\begin{tabular}{lcccccc}
\hline & $\mathbf{2 0 0 0}$ & $\mathbf{2 0 0 1}$ & $\mathbf{2 0 0 2}$ & $\mathbf{2 0 0 3}$ & $\mathbf{2 0 0 4}$ & $\mathbf{2 0 0 5}$ \\
\hline $\begin{array}{l}\text { Pupil-teacher ratio } \\
\text { Uganda }\end{array}$ & 59 & 54 & 53 & 52 & 50 & 50 \\
Zambia & 49 & 52 & 53 & 55 & 55 & 56 \\
$\begin{array}{l}\text { Pupil-classroom ratio } \\
\text { Uganda }\end{array}$ & 108 & 95 & 87 & 87 & 79 & 74 \\
Zambia & 63 & 67 & 71 & 78 & 80 & 86 \\
Source EMIS, MoES (Uganda); MoE (Zambia). & & & & &
\end{tabular}


Table 3 Grade 7 examinations 2000-2006 (average scores).

\begin{tabular}{|c|c|c|c|c|c|c|c|}
\hline & 2000 & 2001 & 2002 & 2003 & 2004 & 2005 & 2006 \\
\hline \multicolumn{8}{|c|}{ Candidates } \\
\hline Uganda & 305 & 350 & 402 & 407 & 434 & 446 & 434 \\
\hline Zambia & 181 & 193 & 200 & 225 & 247 & 272 & 294 \\
\hline \multicolumn{8}{|c|}{ Exam results English } \\
\hline Uganda & & $41 \%$ & $39 \%$ & $44 \%$ & $38 \%$ & $44 \%$ & \\
\hline Zambia & & $50 \%$ & & $47 \%$ & & $50 \%$ & $50 \%$ \\
\hline \multicolumn{8}{|c|}{ Exam results Maths } \\
\hline Uganda & & $33 \%$ & $36 \%$ & $36 \%$ & $35 \%$ & $29 \%$ & \\
\hline Zambia & & $51 \%$ & & $48 \%$ & & $47 \%$ & $44 \%$ \\
\hline
\end{tabular}

"The figures suggest that examination results are better in Zambia than in Uganda. However, both countries have their own curriculum and examinations so the data are not comparable. In the international SACMEQ test in 2000, pupils from Uganda had better results for reading and for maths.

S UNEB (Uganda National Examinations Board), Uganda; ECZ (Examinations Council of Zambia), Zambia.

2005 and the pupil-classroom ratio from 108:1 to 74:1. In 2000, on average four children had to share one book for each subject. In 2005, this ratio was reduced to 2.7:1.

In Zambia, the growth of enrolments came later and was more moderate. Between 1995 and 2000 the total number of children enrolled in primary education was stable. With a growing population, this meant decreasing enrolment rates. From 2000 onwards the enrolments started to grow, partly as a result of the government policy, partly as a result of the growth of community schools. Community schools account for about 22 per cent of the increase in enrolments in basic schools (including grades 8 and 9) between 2000 and 2005. In 2000, about one in ten (new) entrants to grade 1 went to a community school; in 2005 this figure had increased to more than one in five.

The total growth had a negative effect on the quality of education. With increased funding and two investment plans, the Basic Education Sub Sector Investment Plan (BESSIP) and the Ministry of Education Strategic Plan (MoESP), the government and donors sought to redress the negative effects of the increase in enrolments and to improve the quality of education. Many new teachers were recruited, resulting in an increase from 37,000 in 2000 to 50,000 in 2005 . The number of classrooms increased from 25,000 in 2002 to 33,000 in 2005. However, the investments could not keep pace with the large growth of enrolments. Despite the high investments in books and classrooms, there are still enormous shortages. Pupil-classroom ratios are far too high. In 2002, this ratio was 71 pupils to 1 classroom; in 2005 this figure had increased to 86 pupils per classroom. The total number of books for English increased by more than 30 per cent, but the number of books for mathematics remained stable. Many more books are needed, especially for mathematics. Despite the increase in the number of teachers, pupil-teacher ratios rose from 49:1 in 2000 to $56: 1$ in 2005. In order to cope with the shortage of classrooms and teachers, many schools still have double shifts in the lower grades, thereby reducing the contact time to no more than 2-3 hours per day.

As a result of the large growth in enrolments, Zambia came much closer to the realisation of the MDGs on education. In 1999, about one in three children did not go to school; in 2005, this figure had decreased to less than one in ten. The dropout rate has declined as well. Female dropout has changed from 4.9 per cent in 2000 to 3.0 per cent in 2005 and male dropout reduced in the same period from 4.6 per cent to 2.5 per cent. As a result, completion rates at grade 7 increased from 67 per cent to 82 per cent. The completion rate at grade 9 is much lower, but increased as well. Girls did catch up with boys. The female-male ratio in primary education improved from 1:1.09 in 1999 to 1:1.04 in 2005. Now, there is almost parity in primary education. There are, however, large differences by 
Figure 1 Pupil-teacher ratio by the incidence of poverty (Zambia, districts, 2005)

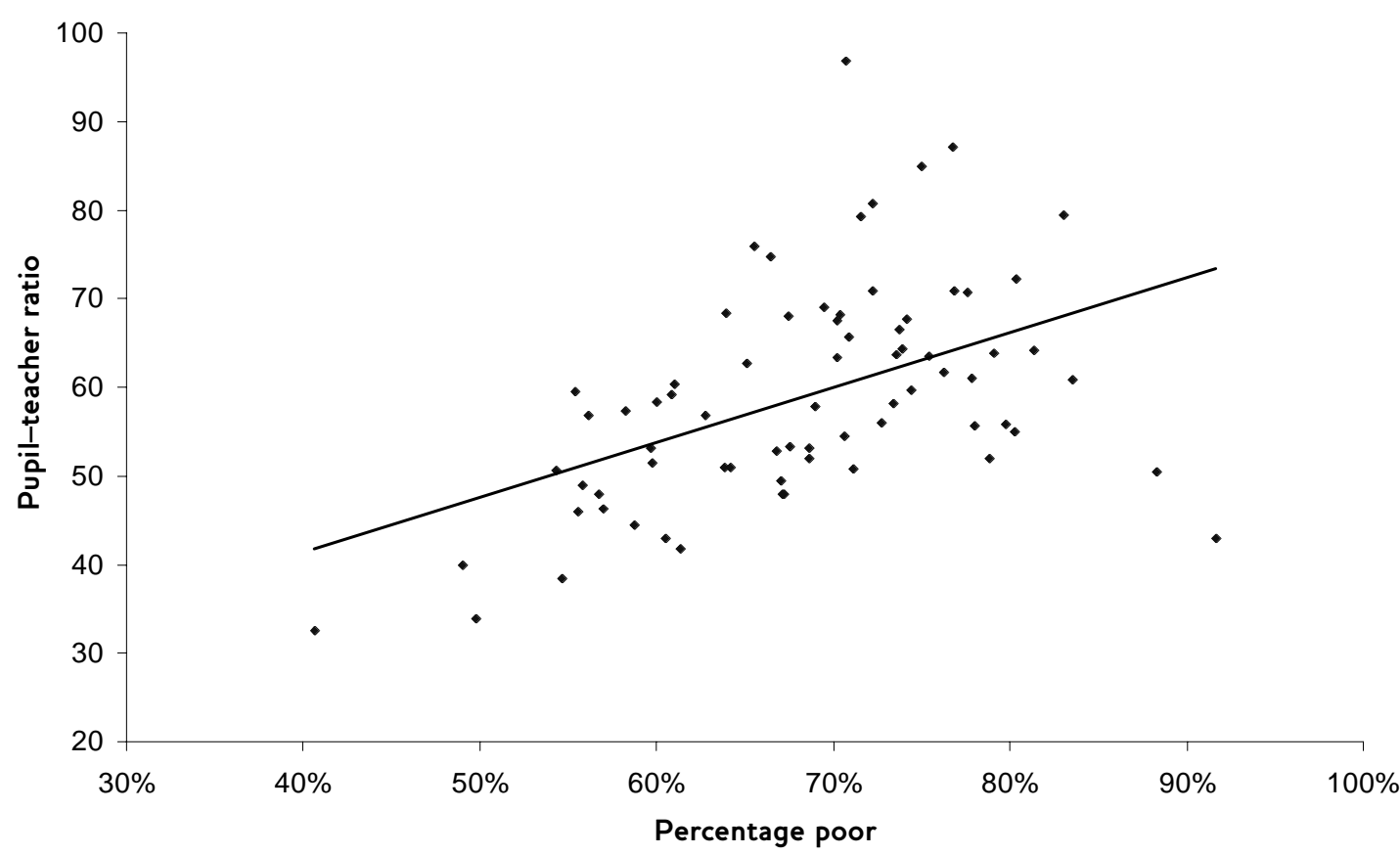

MoE / Computation IOB.

grade and by province. In almost every province, the female-male ratio is close to 1 at the lower grades (1-4), but it drops at the higher grades. At the national level, test and examination results remained stable, the increase in enrolments and the large growth of the number of examination candidates notwithstanding. The quality of education remains low, however. About 70 per cent of the pupils at grade 5 do not attain the minimum level of performance for English and no more than 6 per cent achieve the desirable levels. For maths, the test results improve, but examination results show an opposite (deteriorating) trend. The national assessments do not seem to recognise this development. Finally, though results are stable at the national level, they are not at the provincial level. Even at the provincial level, there are relatively large fluctuations from year to year and this suggests a more fundamental problem: at lower aggregate levels, learning achievements are not stable.

In Uganda, the official net enrolment rate increased to more than 90 per cent. The gender gap narrowed and in 2005 the country achieved gender parity for primary education. The percentage of pupils that passed the primary leaving exam improved from 74 per cent in 2001 to 82 per cent in 2006. Average test and examination results improve gradually. Nevertheless, the country still faces many challenges. First of all, although net enrolment rates seem to be high, pupil attendance rates are low. Dropout (about 10-15 per cent) and repetition (about 14 per cent) are high, resulting in low progression and completion rates. Moreover, although there seems to be a slight improvement in learning achievements, the quality of education remains low. Average scores on tests and primary leaving examinations are below 40 per cent. In 2005, the average result for mathematics for the primary leaving examination was even below 30 per cent. The only reason that most children pass the primary leaving examination is the low level required. This policy may prevent repetition, but many children leave school without mastering literacy and mathematics.

In both countries, the allocation of teachers between schools and within schools is not very efficient. In Uganda, the higher classes may have two or even three teachers, while the lower classes have one teacher for more than hundred children. Zambia has 


\section{Figure 2 Total primary enrolment by socioeconomic position (at ward level)}

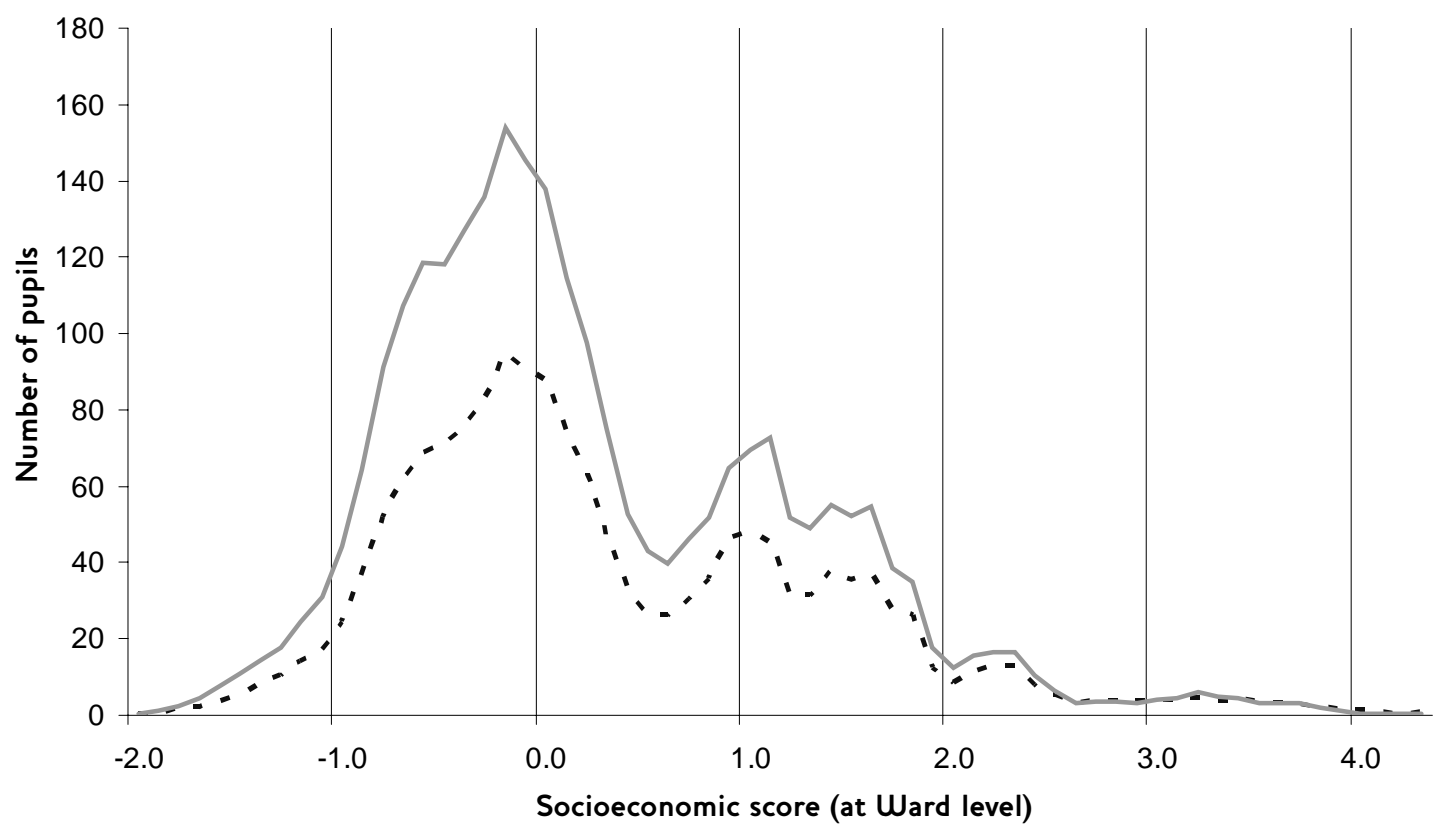

$$
-2005
$$

EMIS (Education Management Information System) (2000-2005); CSO (Central Statistical Office), Population and Housing Census (2000).

double shifts in the lower grades. This distribution reflects a bias towards passing examinations at grade 7 . It does not reflect the importance of smaller classes for the youngest children in the initial reading process. Pedagogically, it makes more sense to reduce pupil-teacher ratios (PTRs) in lower grades. Moreover, in both countries regional disparities remain high. There are large differences between schools and regions. PTRs are much higher in remote rural areas than in urban areas. The allocation of teachers is regressive, with the highest PTRs in the poorest districts (see Figure 1 and Winkler 2007 for Uganda)

\section{Impact}

\subsection{Reaching the poor}

An important effect of the growth of enrolments was, first of all, that more children of a poor socioeconomic background got access to education. In both countries, children from the poorer regions especially had the highest increase in enrolments. Figure 2 gives a presentation of the total enrolment in primary education in Zambia in 2000 and 2005 by socioeconomic position (at the ward level). These socioeconomic positions (or scores) have been calculated from the Population and Housing Census 2000 and include information on the educational attainment and job positions of the heads of households at the ward level. The scores are calculated at the ward level and standardised. ${ }^{5}$ People in wards with a score below 0 are on average less educated and have a paid job less often.

Although the analysis is at the ward level and not at the individual household level, the figure has a lognormal distribution, just like in many income distributions. The more backward regions had a relatively large increase in enrolments. In 2000, 49 per cent of the pupils lived in regions with a (constructed) socioeconomic score that was below 0; in 2005 this figure had increased to 53 per cent. Almost 60 per cent of the growth of enrolments came from the most backward regions. In the wards at the upper end (at the right of the figure), the number of pupils in primary schools hardly increased. This is precisely what one would expect, because enrolment rates were already highest in the most prosperous areas. 
Table 4 Estimated enrolment shares by wealth quintile (2000 and 2005)

\begin{tabular}{|c|c|c|c|c|c|}
\hline & $\begin{array}{l}\text { Net enrolment } \\
\text { rate (2000) (\%) }\end{array}$ & $\begin{array}{l}\text { Share in total } \\
\text { enrolment } \\
(2000)(\%)\end{array}$ & $\begin{array}{c}\text { Estimated share } \\
\text { in grade } 7 \\
\text { enrolment } \\
(2000)(\%)\end{array}$ & $\begin{array}{l}\text { Estimated } \\
\text { share in total } \\
\text { enrolment } \\
(2005)(\%)\end{array}$ & $\begin{array}{c}\text { Estimated share } \\
\text { in grade } 7 \\
\text { enrolment } \\
(2005)(\%)\end{array}$ \\
\hline Quintile I & 51 & 15 & 10 & 18 & 15 \\
\hline Quintile II & 58 & 17 & 14 & 20 & 17 \\
\hline Quintile III & 65 & 20 & 19 & 20 & 20 \\
\hline Quintile IV & 73 & 22 & 25 & 21 & 22 \\
\hline Quintile V & 87 & 26 & 32 & 21 & 26 \\
\hline Total & $67 \%$ & $100 \%$ & $100 \%$ & $100 \%$ & $100 \%$ \\
\hline
\end{tabular}

In 2000, the distribution of grade 7 pupils was more skewed towards the relatively prosperous wards than the distribution of all primary pupils. That year 49 per cent of the pupils came from the wards with a socioeconomic score less than 0 , but for grade 7 pupils this was no more than 41 per cent. In 2005, this figure had increased to 45 per cent. Other research shows that many children, who had left school because their parents could not meet the fees charged, returned to school after the implementation of FBE (Free Basic Education) (Mwansa et al. 2004: 22).

The effect at the ward level seems to be modest, but an analysis at an aggregate level tends to underestimate the real effects: within each ward there is probably the same kind of relation between socioeconomic position and enrolment. The Demographic and Health Survey of 2002 gives some information on (net) enrolment rates in 2000 by wealth quintile. Combining this distribution with the development of enrolments at the ward level allows estimates of the development of the share of separate wealth quintiles in total enrolments. For instance, while the wards with the lowest socioeconomic scores in 2000 enrolled 15 per cent of the pupils, they only accounted for 10 per cent of grade 7 enrolments. In 2000, 15 per cent of the pupils in primary education came from the poorest wealth quintile. Using the information at the ward level, it is assumed that 10 per cent of the grade 7 pupils came from the poorest wealth quintile. The distributions of enrolment by wealth quintile can be used to calculate the distribution for 2005. About 70 per cent of the total increase of 1 million children cannot be explained by population growth. And given the relatively high enrolment rates of the highest wealth quintiles, the growth had to come from children from the poorest wealth quintiles. This conclusion is consistent with the results at the ward level.

The increased access to education of the poorest groups in society normally has a negative effect on the average examination and test results. There is a positive correlation between educational background and income of the parents and test and examination results of the pupils (see White 2004 for the same point with respect to Ghana). Precisely this effect may explain why, in the short run, in many developing countries the effects of increased attention to education may seem to be disappointing. This effect is an example of 'vanishing benefits': the results are there, although they do not seem to be there (see Ravallion 2001). Regression analyses for Uganda and Zambia show a significant relation between income, education of the parents and test and examination results of pupils. In 2005 in Zambia, the examination results for English of the 20 per cent of pupils from the most developed regions (as measured by the socioeconomic score) were on average 20 per cent higher than the results of the lowest 40 per cent.

Figure 3 gives a presentation of the relation between socioeconomic score and examination results for English. The points in the figure denote the mean examination result for English in the wards for each 


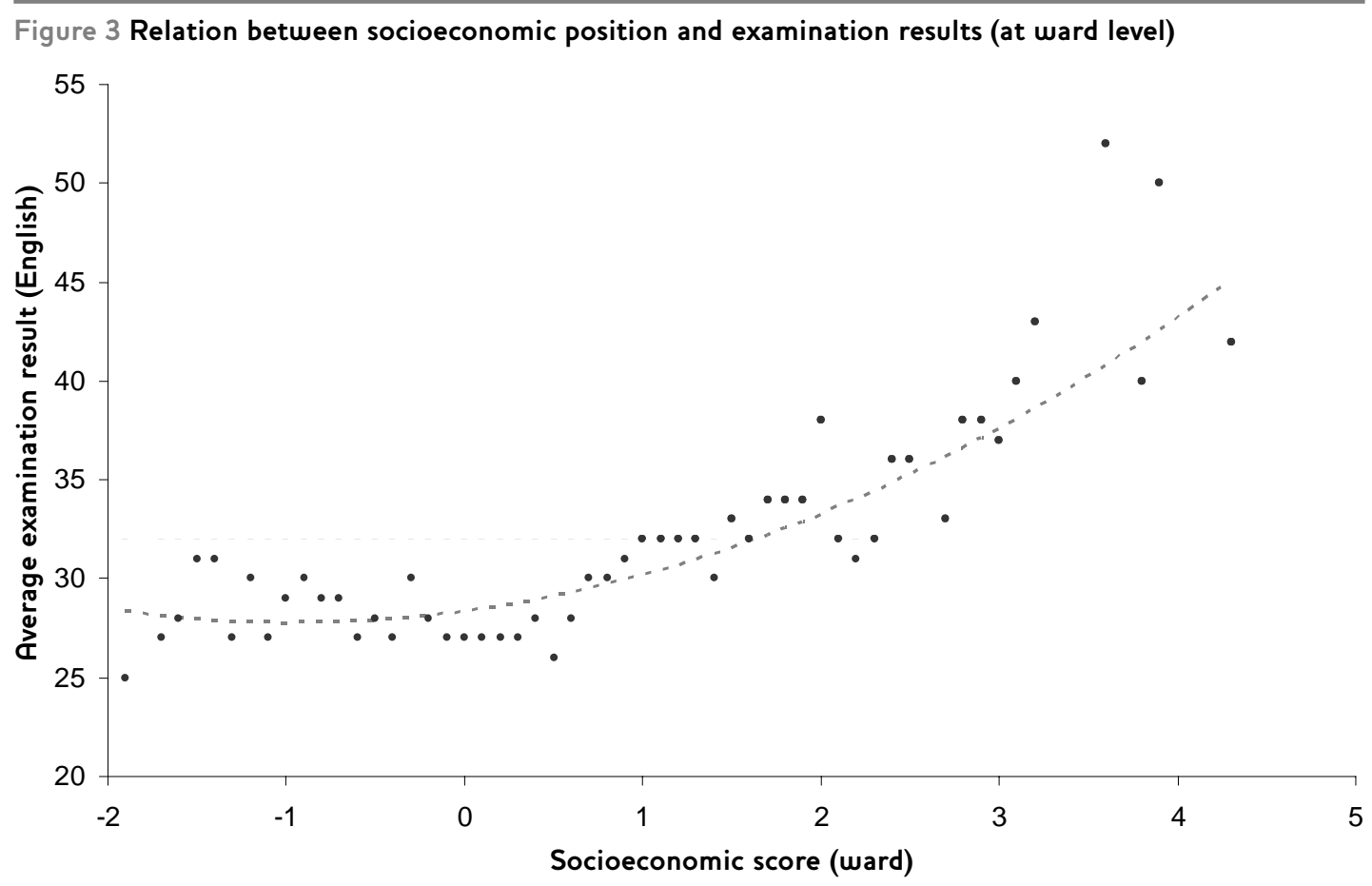

Source EMIS (2000-2005); CSO, Population and Housing Census (2000).

socioeconomic score (weighted by the number of examination candidates in the wards). At the lower level, there is no relation, but above a score of about 0 , the average results at the ward level improve with the score on the constructed (socioeconomic) variable.

Unfortunately, we do not have information on the average examination results by income or educational attainment at the household level. Nevertheless, such a figure would certainly lead to larger differences, with higher figures for the children of well-educated parents with a relatively high income and lower figures for the poorest households. Taking this into account, the total effect of the increased access of the children of poorest households to primary education leads to a reduction of average test and examination figures of about 4-5 per cent. This effect does not seem to be very large, but one has to realise that at the same time total enrolment did grow by 60 per cent.

\subsection{Effectiveness of interventions}

How effective were the investments in education? Which interventions have the largest impact on educational outputs? Both studies analyse the effects of interventions on access (dropout, repetition, progression and completion) and learning achievements (test and examination results), taking into account the influences of other determinants. The main instruments are influencing the number of teachers, schools, classrooms and books; the education and training of teachers; and the improvement of the quality of the school and of school management. The analyses are based on a regression approach, combining several datasets, especially EMIS data (school census data), test and examination results (grade 7 examinations) and population census data. Population census data have been aggregated and included at the parish (Uganda) and ward (Zambia) level. ${ }^{6}$

Tables 5 and 6 show some of the regression results for Uganda and Zambia. In these examples, the (average) examination results for English and maths are the dependent variables. The analysis for Uganda is based on figures for 2003, 2004 and 2005; the Zambia analysis is restricted to $2005 .{ }^{7}$ The analyses include two variables that have been scaled by dividing the original variables by the number of pupils: the teacher-pupil ratio and the pupil-books ratio. In the literature, there 
Table 5 Variables explaining examination results for English and for mathematics (2003-2005; GLS [Generalised Least Squares])

\begin{tabular}{|c|c|c|c|c|c|c|}
\hline \multirow[t]{2}{*}{ Variable } & \multicolumn{2}{|c|}{ English } & \multicolumn{4}{|c|}{ Mathematics } \\
\hline & Coefficient & z-statistic & & Coefficient & z-statistic & \\
\hline Book-pupil ratio English & 0.22 & 15.4 & $* *$ & & & \\
\hline Book-pupil ratio Mathematics & & & & 0.16 & 11.9 & ** \\
\hline Teacher-pupil ratio & 9.60 & 6.5 & $* *$ & 6.44 & 4.9 & ** \\
\hline Education level teachers & 0.10 & 3.8 & $* *$ & 0.14 & 5.8 & $* *$ \\
\hline Teacher training & 0.12 & 2.4 & * & 0.08 & 2.3 & * \\
\hline Head teacher qualification & 0.08 & 10.7 & $* *$ & 0.07 & 10.3 & ** \\
\hline Availability of classrooms & 0.27 & 7.6 & $* *$ & 0.17 & 5.3 & ** \\
\hline Availability of toilets & 0.07 & 2.4 & $*$ & 0.08 & 2.9 & ** \\
\hline Community schools & 0.59 & 6.0 & $* *$ & 0.39 & 4.5 & ** \\
\hline Private schools & 1.68 & 21.7 & $* *$ & 1.48 & 22.6 & ** \\
\hline Distance to the nearest school & -0.06 & -7.9 & $* *$ & -0.04 & -5.8 & ** \\
\hline Urban & 0.87 & 14.7 & $* *$ & 0.55 & 10.8 & ** \\
\hline Peri-urban & 0.69 & 17.4 & $* *$ & 0.40 & 11.8 & ** \\
\hline North & 0.33 & 6.8 & $* *$ & -0.08 & -1.9 & \\
\hline East & 0.29 & 6.9 & ** & -0.02 & 0.6 & \\
\hline West & 0.52 & 12.8 & $* *$ & 0.46 & 13.9 & ** \\
\hline Masindi & 1.61 & 14.9 & $* *$ & 0.80 & 9.1 & ** \\
\hline Socioeconomic differences & 0.61 & 29.0 & $* *$ & 0.33 & 18.8 & ** \\
\hline Proportion female & -0.04 & -0.3 & & -0.27 & -4.1 & ** \\
\hline Proportion orphans & 0.11 & 1.0 & & 0.10 & 1.0 & \\
\hline 2003 & 0.11 & 6.7 & $* *$ & 0.69 & 47.8 & ** \\
\hline 2004 & -0.68 & -48.8 & $* *$ & 0.68 & 52.5 & ** \\
\hline Constant & 1.88 & 21.7 & $* *$ & 0.92 & 12.8 & ** \\
\hline$N=$ & 17,560 & & & 17,560 & & \\
\hline $\mathrm{R}_{2}=$ & 0.42 & & & 0.32 & & \\
\hline Wald $\mathrm{Chi}_{2}=$ & 9,442 & & & 7,060 & & \\
\hline
\end{tabular}

${ }^{*}$ significant a $\mathrm{p}<0.05{ }^{* *}$ significant at $\mathrm{p}<0.01$. 
Table 6 Effect of policy interventions on English and maths examination results (2005)

\begin{tabular}{|c|c|c|c|c|c|c|}
\hline & & & & $\mathrm{Ma}$ & atics & \\
\hline & Coefficient & t-statistic & & Coefficient & t-statistic & \\
\hline Private & 6.3 & 6.2 & $* *$ & 5.7 & 6.2 & $* *$ \\
\hline Grant-aided & 0.2 & 0.2 & & -0.2 & -0.1 & \\
\hline Community & -2.7 & -0.7 & & -5.9 & -1.8 & \\
\hline Teacher-pupil ratio & 122.9 & 4.3 & $* *$ & 41.6 & 1.6 & \\
\hline Classroom-teacher ratio & 3.0 & 3.6 & $* *$ & 1.7 & 2.3 & $*$ \\
\hline Double class teachers (\%) & 0.7 & 0.9 & & 0.8 & 1.2 & \\
\hline Teacher training & 0.03 & 0.03 & & -0.5 & -0.8 & \\
\hline Proportion teachers with diploma & 4.2 & 3.5 & $* *$ & 2.1 & 2.0 & $*$ \\
\hline Teacher age & -0.1 & -2.5 & * & -0.1 & -1.7 & \\
\hline Teacher attrition rate & 2.5 & 2.4 & * & 1.4 & 1.5 & \\
\hline Prof. qualific. head teacher & -1.1 & -2.7 & $* *$ & -0.9 & -2.5 & $*$ \\
\hline Book-pupil ratio & -0.1 & -0.3 & & 1.4 & 2.9 & $* *$ \\
\hline School size & -0.4 & -0.9 & & -1.0 & -2.7 & $* *$ \\
\hline Candidates/G 7 pupils $^{\dagger}$ & -3.1 & -2.0 & * & -3.0 & -2.2 & $*$ \\
\hline Mean age candidates & -1.0 & -4.8 & $* *$ & -0.6 & -3.2 & $* *$ \\
\hline Proportion female candidates & -0.4 & -0.3 & & -1.9 & -1.3 & \\
\hline Proportion orphans & -3.1 & -2.0 & $*$ & -1.6 & -1.1 & \\
\hline Socioeconomic status & 0.7 & 2.9 & $* *$ & 0.3 & 1.3 & \\
\hline Urban & 2.4 & 4.4 & $* *$ & 1.1 & 2.2 & $*$ \\
\hline Copperbelt & -2.3 & -3.5 & $* *$ & -0.9 & -1.5 & \\
\hline Central Province & -1.7 & -2.7 & $* *$ & -0.9 & -1.5 & \\
\hline Southern Province & -4.0 & -6.3 & $* *$ & -2.8 & -4.9 & $* *$ \\
\hline Luapula & 0.5 & 0.7 & & 2.6 & 3.9 & $* *$ \\
\hline Northern Province & -3.4 & -5.1 & $* *$ & -1.8 & -3.0 & $* *$ \\
\hline Eastern Province & -2.8 & -3.9 & $* *$ & -1.2 & -1.9 & * \\
\hline North Western Province & 0.2 & 0.3 & & -0.1 & -.1 & \\
\hline Western Province & 0.7 & 0.8 & & 1.3 & 1.7 & \\
\hline $\begin{array}{l}\text { Constant } \\
\mathrm{R}^{2} \text { adjusted } \\
\mathrm{F}\end{array}$ & $\begin{array}{r}37.3 \\
0.31 \\
25\end{array}$ & 9.0 & $* *$ & $\begin{array}{r}40.4 \\
0.17 \\
12\end{array}$ & 10.6 & $* *$ \\
\hline N & 1,424 & & & 1,424 & & \\
\hline $\begin{array}{l}{ }^{*} \text { significant at } p<0.05 \% ;{ }^{* *} \text { significa } \\
+ \text { In Zambia many pupils cannot do } \\
\text { examination centre. The included v }\end{array}$ & $\begin{array}{l}\text { int at } p<0.01 \\
\text { their exam at } \\
\text { ariable correct }\end{array}$ & $\begin{array}{l}\text { own schoc } \\
\text { this effect. }\end{array}$ & & ust go to anc & chool, a so & \\
\hline
\end{tabular}

46 de Kemp Analysing the Effectiveness of Sector Support: Primary Education in Uganda and Zambia 
has been a long debate about the relation between class size and learning achievement. This debate is mainly based on evidence in industrialised countries and seems to be inconclusive. ${ }^{8}$ Michaelowa (2003) suggests a concave quadratic function for the relation between class size and education quality. In this specification, pupils get the best results in a class size of about 60 . However, for both studies, we did find an inverse (convex) relation between pupil-teacher ratio and learning achievements (or a linear relation between teacher-pupil ratio and learning achievements). The pupil-classroom ratio is not included in the analysis because it is highly correlated with the pupil-teacher ratio. Instead, the studies use a different indicator. The Uganda study uses an indicator that depicts a relative shortage of classrooms (or the number of classrooms divided by the number of classrooms needed). The Zambia study uses the classroom-teacher ratio. The analyses include several other teacher characteristics: the educational background or professional qualification of teachers, the percentage of teachers with additional training, the age of teachers, and (in the case of Zambia) teacher attrition. The analysis for Zambia includes, moreover, the percentage of teachers with double classes. As a management variable, the qualification of the head teacher is included as well as the school type: government, private, grant aided, or community. The analyses include several pupil characteristics as well: the average age of the examination candidates, the percentage of female candidates, and the percentage of orphans in grade 7 . Related to these pupil characteristics are the regional variables: the relative socioeconomic position of the parish or ward, the urban/rural distinction, and the region. The analysis for Uganda also includes the distance to the next school (as a proxy for the average distance pupils have to walk to the school).

The analyses confirm the effectiveness of investments in teachers, classrooms, books, and other school facilities. The results are in line with the findings of the IEG (Independent Evaluation Group) of the World Bank for basic education in Ghana (White 2004). High pupil-teacher ratios and high pupil-classroom ratios have a negative effect on learning achievement. Schools with double shifts (as measured by the proportion of double class teachers) do not have significantly better results than schools with lower double shift ratios. There is a significant effect of teacher education and teacher training. Schools with high percentages of teachers that have had training in the previous year perform better. In both countries, many children have to share their books with other pupils, but the analysis shows that they perform better when all children have their own books. In Uganda, the investment in books has the expected effect. In the case of Zambia, however, the study only found a significant effect for maths books. English books do not seem to be very effective and this points to a problem in the distribution and utilisation of books. It appears that in many Zambian schools (as well as in Uganda) books are not used effectively. They may be locked away and large shortages may be an explanation for this behaviour. There is evidence of poor textbook usage with continuing emphasis on learning by rote (Ward 2006). The teacher training colleges should pay more attention to the effective use of books.

Three variables point to the effect of good management. First of all, private schools perform better than public schools, grant-aided schools, or community schools. Privately funded schools outperform government schools by 20-40 per cent, even after taking into account all the other variables in the model. Second, the head teacher qualification proves to be significant, especially in the Uganda study. The cross-section analysis for Zambia did not find a positive effect of the head teacher qualification on average examination results, but for the test results (at grade 5) the effect was positive and significant. Moreover, a double difference estimate produced for the examination figures has a positive and significant effect as well. Third, for the Uganda case study, results in Masindi district, with a project that is directed at the improvement of the quality of school management, are better than the results in other districts. These results suggest that improved management is the key to an improvement of education. In 2000, an NGO in Uganda started an education development project in close cooperation with the Masindi District Education Office and the Education Standards Agency. The project focused its activities on enhancing the quality of education management at both school and district level through school management training, training and support in school inspection procedures, and the development of information management systems at district level. An analysis based on propensity score matching shows that pupils in schools that are part of the project have about 50 per cent higher examination scores than pupils in comparable schools in Uganda (see Annex, Table I). The (relatively) good results are realised by good school management, 
motivated teachers and adequate monitoring (by the district inspectors). An additional analysis on the impact of (16) management variables shows that management is highly (and positively) correlated with examination results.

Results for Zambia point to the effect of good management as well, though in a totally different manner. In many schools in Zambia, average examination results have large fluctuations from year to year. Fluctuations of 30-40 per cent are no exception. The growth of enrolments and a high teacher turnover cannot explain these fluctuations. They point to several weaknesses that have to do with capacity constraints, severe underfunding, a lack of qualified and motivated teachers and head teachers, and a lack of effective management at the school and district level.

The Uganda study gives estimates of the costeffectiveness of interventions, as well. It must be stressed that there are no general rules: what is most cost-effective will always depend on the specific situation. Nevertheless, on the basis of the analysis it is possible to present some general findings. First of all, interventions (investments) are much more effective when the school has good management. Therefore, the main conclusion of this study is that it is important to invest in the quality of management. When the quality of management improves, the effectiveness of other interventions will increase as well. Investing in the quality of management means training, an effective support structure at the district level and an effective inspection apparatus. Second, it pays to invest in books. Books are a cost-effective instrument in raising the learning achievements of pupils. In order to make sure that books will be used, it is important that schools have enough copies. Moreover, the effectiveness of books will increase when teacher training is directed to this. Third, teacher training is a cost-effective way to improve results. Well-trained teachers seem to feel more responsible and have lower rates of absenteeism, and schools with well-trained teachers have better results. The reduction of the pupil-teacher ratio is effective as well, especially in an environment with good management. Without this, the effects of lowering the pupil-teacher ratio may be disappointing.

\section{Conclusions}

The studies show that Uganda and Zambia succeeded in enhancing access to primary education through the implementation of the development plans and the abolition of school fees. The growth of enrolments notwithstanding, pupil-teacher ratios, pupil-classroom ratios and pupil-book ratios could decline in Uganda. It can be expected that they will decline in Zambia within the next five years as a result of the decision to enlarge the budgets for education. Nevertheless, both countries face several challenges. The quality of education is low. In Uganda, attendance and progression rates are low and dropout and repetition high. The absenteeism among teachers appears to be higher than elsewhere and this has an enormous negative impact on learning achievements. In Zambia pupils at the lower grades have an extremely short contact time as a result of double shifts. Capacity at all levels is low and the average test and examination results of the schools show large fluctuations. The impact analyses show that it pays to invest in teachers, books and classrooms. Nevertheless, these investments will be much more effective when both countries succeed in improving the quality of school and district management and the quality of the inspectorate at the same time.

Another lesson is that it is important that development partners have realistic expectations of the possibilities to improve access and quality at the same time. SWAp (Sector Wide Approach) and GBS (General Budget Support) are based on the assumption that the MoES and local governments have the capacity to implement the necessary measures effectively and efficiently and that these measures will have visible effects within a few years. Development agencies may be tempted to compare the sector results with the results of their own projects. However, the fragmented project approach could never have contributed in the same way to the growth of enrolments and therefore to the realisation of MDG 2 .

Both studies show that better monitoring information makes it possible to analyse the results of the sector and that it can contribute to both functions of an evaluation: accountability and, above all, lesson learning. There are many methodological problems, but we cannot urge the ministries to collect management information on a yearly basis and then simply tell them that this information is useless for evaluation purposes. Secondary data increasingly become valuable sources for impact evaluations. The challenge is to improve the methods for evaluating impact using these data. Denying their value and insisting on a laboratory approach seems to be a regression. 
Annex

Table I Comparison of examination results for Masindi project schools and other schools in Uganda

\begin{tabular}{|c|c|c|c|c|c|c|}
\hline & & $\begin{array}{c}\text { Project } \\
\text { schools in } \\
\text { Masindi }\end{array}$ & $\begin{array}{c}\text { Control } \\
\text { group }\end{array}$ & $\begin{array}{c}\text { Other } \\
\text { schools in } \\
\text { Masindi }\end{array}$ & $\begin{array}{l}\text { Other } \\
\text { schools } \\
\text { outside } \\
\text { Masindi }\end{array}$ & t-value* \\
\hline \multirow[t]{3}{*}{ English } & 2003 & 5.5 & 3.4 & 4.1 & 3.3 & 7.6 \\
\hline & 2004 & 4.6 & 2.8 & 3.4 & 2.6 & 6.4 \\
\hline & 2005 & 5.1 & 3.5 & 4.3 & 3.3 & 8.1 \\
\hline \multirow[t]{3}{*}{ Mathematics } & 2003 & 3.8 & 2.5 & 2.8 & 2.5 & 5.9 \\
\hline & 2004 & 3.8 & 2.6 & 2.9 & 2.5 & 5.7 \\
\hline & 2005 & 3.0 & 1.9 & 2.3 & 1.9 & 7.1 \\
\hline \multirow[t]{3}{*}{ Science } & 2003 & 5.6 & 3.5 & 4.3 & 3.5 & 7.2 \\
\hline & 2004 & 5.3 & 3.6 & 4.4 & 3.5 & 6.0 \\
\hline & 2005 & 5.8 & 3.9 & 5.0 & 3.9 & 9.8 \\
\hline \multirow[t]{3}{*}{ Social Studies } & 2003 & 6.2 & 4.1 & 5.1 & 3.9 & 7.8 \\
\hline & 2004 & 5.9 & 4.0 & 4.8 & 3.7 & 6.6 \\
\hline & 2005 & 5.5 & 3.5 & 4.5 & 3.4 & 10.4 \\
\hline \multirow[t]{3}{*}{ Total } & 2003 & 5.5 & 3.4 & 4.1 & 3.3 & 7.6 \\
\hline & 2004 & 4.9 & 3.3 & 3.9 & 3.1 & 6.6 \\
\hline & 2005 & 4.9 & 3.2 & 4.0 & 3.1 & 8.1 \\
\hline
\end{tabular}

* On the basis of a t-test for the significance of the difference between project group and control group.

Source EMIS / UNEB / LCD (Link Community Development)/computation IOB.

\section{Notes}

* Evaluator of the Policy and Operations Evaluation Department $(\mathrm{IOB})$ of the Netherlands Ministry of Foreign Affairs. IOB has carried out both studies in close cooperation with the Ministry of Education in each country. Moreover, Jan Willem Gunning and Chris Elbers (Vrjie Universiteit Amsterdam) did a large part of the analysis for the Zambia study and they advised on the Uganda study. For the Uganda study, IOB collaborated with several local officials and especially with Joseph Eilor, who acted as the counterpart and co-author of the Uganda study. In addition, the author is grateful to Henri Jorritsma and Howard White for their comments on a first draft.

1 For further details see: IOB/AIID (Amsterdam Institute for International Development) (2007).

2 SACMEQ is the Southern and Eastern Africa Consortium for Monitoring Educational Quality. The consortium (of 15 Ministries of Education) tests the progress of pupils on reading and mathematics.
3 This approach is not new and has been applied by Case and Deaton (1998) and Hoxby (2000). See Webbink (2005).

4 Uganda has a population of about 27 million and Zambia has a population of 11 million people.

5 With principal components analysis the socioeconomic variable has been calculated using the literacy of adults, the percentage of adults that went to any institution of learning, the highest level of academic education (grade), the percentage of adults with a certificate, diploma or degree, the percentage of persons with a paid job in the last year, occupation (percentage with a professional, administrative, or clerical job), and the percentage of persons with paid work. The analysis is restricted to the heads of the households. The method results in a score for each ward with a mean of $\mathrm{O}$ and a standard deviation of 1 .

6 Several variables that denote the socioeconomic status of the head of the household (like job 
status and educational background) have been aggregated and combined using principal components analysis into one socioeconomic variable. See the preceding paragraph for an explanation.

7 The researchers did not have examination figures for 2004, while the 2003 database seems to be

\section{References}

Case, Anne and Deaton, Angus (1998) School Quality and Educational Outcomes in South Africa, Working Paper 993, Princeton: Princeton University

Eilor, Joseph (2004) Education and the Sector-wide Approach in Uganda, Paris: UNESCO

Elbers, Chris and Gunning, Jan Willem (2006) Assessing Budget Support with Statistical Impact Evaluation, Amsterdam: Vrije Universiteit

Glewwe, Paul and Kremer, Michael (2005) Schools, Teachers and Education Outcomes in Developing Countries, CID Working Paper 122, Cambridge: CID

Hanushek, Eric A. (2003) 'The Failure of Input-based Schooling Policies', The Economic Journal 113: 64-98

Hoxby, Caroline Minter (2000) 'Does Competition Among Public Schools Benefit Students and Taxpayers?', American Economic Review 90: 1209-38

IOB/AIID (2008) Impact Evaluation of Primary Education in Zambia, The Hague/Amsterdam: IOB IOB/Ministry of Education and Sports (2008) Impact Evaluation of Primary Education in Uganda, The Hague/Kampala: IOB/MoES

Kingdon, Geeta (2005) 'Education Economics', DFID Economists' Guide, London: DFID

Michaelowa, Katharina (2003) Determinants of Primary Education Quality: What Can we Learn from PASEC for Francophone Sub-Saharan Africa?, Paris: ADEA less reliable. Moreover, free primary education was introduced in Zambia in 2002.

8 See for instance Michaelowa (2003) and Hanushek (2003).

Mwansa, Audrey C.; Kaba, Alex; Zulu, Lucas; Kalokoni, John and Nuirongo, Griffin K. (2004) Free Basic Education (Grades 1-7) Policy Implementation Assessment, Lusaka: MoE

Ravallion, Martin (2001) 'The Mystery of Vanishing Benefits: An Introduction into Impact Evaluation', The World Bank Economic Review 15.1: 115-40

Verspoor, Adriaan M. (ed.) (2006) The Challenge of Learning: Improving the Quality of Basic Education in Sub-Saharan Africa, Paris: ADEA

Ward, Michael; Penny, Alan and Read, Tony (2006) Education Reform in Uganda - 1997-2004. Reflections on Policy, Partnership, Strategy and Implementation, London: DFID

Webbink, Dinand (2005) 'Causal Effects in Education', Journal of Economic Surveys 19.4: 535-60

White, Howard (2004) Books, Buildings, and Learning Outcomes: An Impact Evaluation of World Bank Support to Basic Education in Ghana, Washington DC: OED, The World Bank

White, Howard and Edstrand, Tove (1998) 'Zambia' in Howard White (ed.), Aid and Macroeconomic Performance, Basingstoke: Macmillan

White, Howard; Sinha, Shampa and Flannagan, Ann (2006) A Review of the State of Impact Evaluation, Washington DC: World Bank

Winkler, Donald (2007) The Efficiency of Public Education in Uganda, Washington DC: The World Bank 